\begin{tabular}{|c|c|c|}
\hline PORT SAID ENGINEERING RESEARCH JOURNAL \\
Faculty of Engineering - Port Said University \\
Volume 17 No. 2 September 2013 pp: 41-54
\end{tabular}

\title{
TUROCHARGED DIESEL ENGINE MODEL WITH DYNAMIC PERFORMANCE BASED ON SIMULATION
}

\author{
E.A.F. Baraya ${ }^{\text {, G.A.Z.Mousa }}{ }^{2}$ and SHabban .M.M ${ }^{3}$
}

\begin{abstract}
This paper presents a detailed mathematical model of a Turbocharged Diesel Engine 8M 453C MAK of cutter suction dredger mashour and its governor set in the Suez Canal authority. The developed mathematical model is then employed to investigate the system performances both in steady state and transient. The simulation results are checked and the model is verified using experimental data in case of steady state condition. Simulation runs in order to examine the diesel engine behavior in a variety of operating conditions. Various control scenarios for improved engine operation and efficient running closer to MCR under varies load conditions are investigated. The analysis of the results is established to show features of model and is defined safe operating conditions, in particular those of the turbocharging system. The analyses and the model can be used in finding better design characteristics and in expert operating systems which can analyse different conditions of the system and offer optimum operating conditions in order to prevent unwanted occurrences. By the aid of MATLAB/SIMULINK, the model is running out and the components library has created. The main conclusive points from the simulation model that it shows that the main reason for exhaust gas temperature increase is the reduction of air mass flow rate through the engine. Also it is found that air cooler, exhaust port and exhaust duct and turbine inlet flow area reduction affect on the exhaust gas temperature level.
\end{abstract}

\section{NOMENCLATURE}

\begin{tabular}{ll}
$\mathrm{A}$ & area $\left[\mathrm{m}^{2}\right]$ \\
$\mathrm{i}$ & revolutions per cycle \\
$\mathrm{K}_{\mathrm{p}}$ & proportional gain \\
$\mathrm{K}_{\mathrm{I}}$ & Integral gain \\
$\mathrm{K}_{\mathrm{d}}$ & Derivative gain \\
$\dot{m}$ & Mass flow rate [kg/sec] \\
$\mathrm{N}$ & Rotational speed [r.p.s] \\
$\mathrm{P}_{\mathrm{b}}$ & Break power $\quad$ [watt] \\
$\mathrm{P}_{\mathrm{I}}$ & Indicated power [watt] \\
$\mathrm{p}_{\mathrm{r}}$ & pressure ratio \\
$\mathrm{p}$ & pressure[bar] \\
$\mathrm{Q}$ & torque [Nm] \\
$\mathrm{R}_{\mathrm{N}}$ & gas constant [j/kg.k] \\
$\mathrm{r}_{\mathrm{c}}$ & compression ratio \\
$\mathrm{V}_{\mathrm{dis}}$ & displacement volume of engine $\left[\mathrm{m}^{3}\right.$ ] \\
$\mathrm{T}$ & temperature [k] \\
$\mathrm{t}$ & time [sec] \\
$\mathrm{v}$ & velocity [m/s] \\
$\mathrm{X}_{\mathrm{r}}$ & fuel rack position \\
$\mathrm{Z}_{\mathrm{cyl}}$ & Number of engine cylinders \\
\hline
\end{tabular}

${ }^{I}$ Operation and maintenance in Dredging Department, cutter suctions Dredger Mashour, Suez Canal Authority, Ismailia, Egypt.

E-mail: Eslambaraya@yahoo.com

${ }^{2}$ Department of Mechanical Power Engineering, Faculty of Engineering, Port Said University, Port Said, Egypt.

E-mail:G.A.Z.Mousa@hotmail.co

${ }^{3}$ Department of Mechanical Power Engineering, Faculty of Engineering, Port Said University, Port Said, Egypt.

E-mail:M.M.Shaban@hotmail.com

$\begin{array}{ll}\omega & \text { Engine angular velocity }[\mathrm{rad} / \mathrm{sec}] \\ \rho & \text { Density }\left[\mathrm{kg} / \mathrm{m}^{3}\right] \\ \alpha_{T} & \text { Turbine flow coefficient } \\ \Delta p & \text { Pressure drop [bar] } \\ \varepsilon & \text { Effectiveness } \\ \eta & \text { Efficiency } \\ \eta_{m} & \text { Mechanical efficiency } \\ \eta_{r e l} & \text { Relative efficiency } \\ \eta_{v o l} & \text { Volumetric efficiency } \\ \zeta & \text { Proportion of the chemical energy of the fuel } \\ \text { contained in the exhaust gas. }\end{array}$

\begin{tabular}{ll}
\multicolumn{2}{l}{ Subscripts } \\
a & air \\
AF & air filter \\
AC & air cooler \\
atm & ambient \\
b & brake \\
C & compressor \\
$\mathrm{C}_{\mathrm{d}}$ & discharge coefficient \\
comb & combustion \\
cyl & cylinder \\
Comp & compressor \\
eff & effective \\
exh & exhaust \\
eng & engine
\end{tabular}




$\begin{array}{ll}\text { ep } & \text { exhaust pipe } \\ \text { eq } & \text { equivalent } \\ \text { f } & \text { fuel ,friction factor } \\ \text { GB } & \text { Gear box } \\ \text { Geo } & \text { geometric } \\ \mathrm{H}_{\mathrm{L}} & \text { fuel lower heating value } \\ \text { inl } & \text { inlet } \\ \text { i } & \text { indicated } \\ \text { I } & \text { polar moment of inertia } \\ \text { M } & \text { maximum } \\ \text { O } & \text { initial condition } \\ \text { P } & \text { propeller } \\ \text { SW } & \text { sea water } \\ \text { Sh } & \text { shaft } \\ \text { TC } & \text { turbocharger } \\ \text { tur } & \text { turbine } \\ \text { w } & \text { cooling water } \\ \text { Abbreviations } \\ \text { MCR } & \text { maximum continuous rating } \\ \text { BMEP } & \text { brake mean effective pressure } \\ \text { IMEP } & \text { Indicated mean effective pressure } \\ \text { FMEP } & \text { friction mean effective pressure } \\ \text { BSFC } & \text { brake specific fuel consumption }\end{array}$

\section{INTRODUCTION}

The diesel engines is a type of internal combustion engine, more specifically it is a compression ignition engine, in which the fuel is ignited solely by the high temperature created by compression of the air-fuel mixture. Semin [1] Study on computational modeling of four stroke, 8-cylinder inline direct injection diesel engine is presented. The engine specification is shown in table [1].

The engine with known specification is being modeled using Matlab Simulink. The operational parameters of the engine such as power, torque, specific fuel consumption and mean effective pressure which are dependent to engine speed are being discussed. The procedures of work present in the following paper are shown as flow chat in figure 1.

The validation in transient state of the turbocharged diesel engine model MAK 8M 453C carried out for 4 stroke propeller engine present in Ref. [6]. The steady state results validation with the experimental works carried out at varies engine operating conditions.

The whole engine system is divided into several functional blocks. The sub-models of individual blocks and the dynamic model of engine system are established according to engine working principles and experimental data of the engine modeled. Some empirical equations describing the performance of engines are proposed to simplify the modeling. A diesel engine model with differential equations to calculation the engine crankshaft and turbocharger speeds is used for the modeling of the Diesel engine. The diesel engine is modeled by considering the processes occurring in its parts. The engine parts that have been taken into consideration are shown in figure 2, the engine cylinders, which are connected between the engine inlet manifold and the engine exhaust manifold. The engine turbocharger which consists of the compressor and the turbine connected in common shaft. The engine air cooler, which is located after the compressor in order to cool the hot air exiting the compressor.

The equations presented below are from the general understanding of the engine model thermodynamically and dynamically.

\section{MODELING OF DIESEL ENGINE}

In this section, the mathematical model of the turbocharged diesel engine encountered its components is developed.

\subsection{Model Descriptions}

The principle of modelling the system and different parts is introduced. Based on thermodynamic, dynamics and fluid dynamics phenomena equations. All works are based on these principles. This part is defined with steps in the time domain, as the final model is simulated per cycle, which is more convenient. With this introduction it is easier to understand the modelling process, because as we model it in per cycle, the transfer due to units and steps makes the calculations more complicated.

With the availability of detailed technical data, the engine model is more realistic. The classic dynamic behavior includes inertia of the diesel engine and turbine-compressor system as the main parts. For other subsystems the dynamic behavior is mainly based on the thermodynamic and fluid dynamic behavior. The cylinder model is the most important part. It explains the combustion process inside the cylinder and calculates important operating parameters such as the output power mean effective pressure, break torque, revolution speed, etc. The design and layout of the engine is typical of 8 inline cylinder four stroke diesel engine with an inertial load in the form of a flywheel, and variable load in the form of an electrical generator. To vary the electrical load a load control voltage is used.

There are several assumptions about parameters and processes in this subsystem with which the simulation results are near by the realistic situation. The dynamic behaviour of the turbine and the compressor systems are very complicated. The performance map of the turbine and the compressor system is a common tool used in the modelling. Though the performance map is available from the manufacturer, unfortunately, for different engines such a performance map may be different 


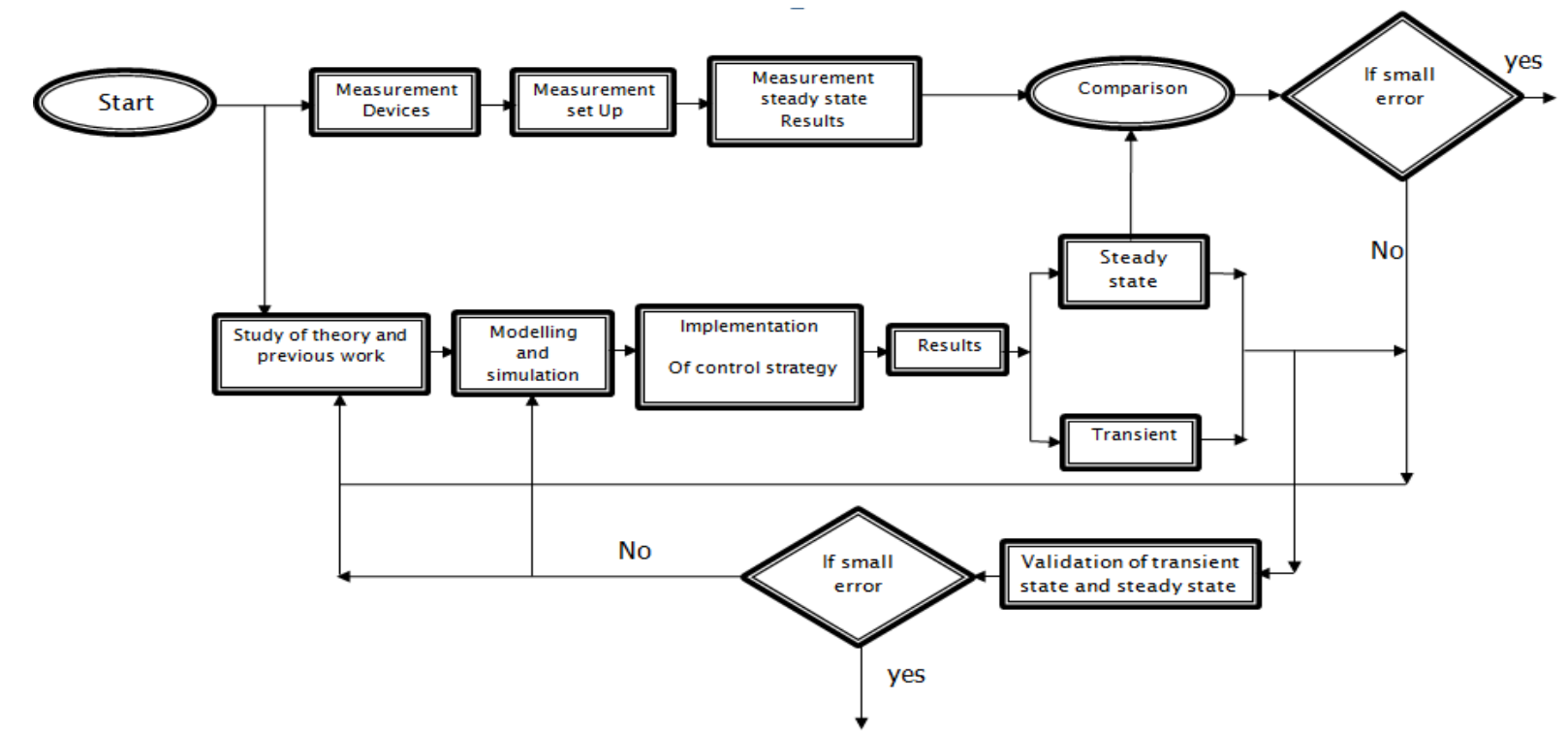

Figure1: Flow chart of present work procedures of modelling and measurement.

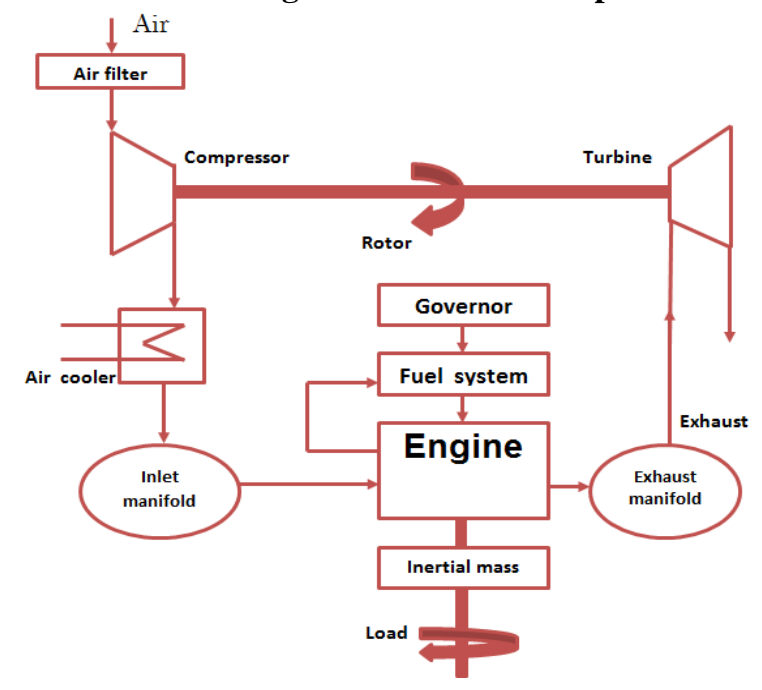

Figure 2: Turbocharger engine parts considered in model

The performances are approximated by constants at operating points in the equations of turbocharger model to simplify the model.

The performance map of the turbine and the compressor system brings the disadvantage that there is no general accurate model applied in a wide field due to variation of operation point in each compressor [13]. A general assumption is used to explain its dynamic action. Load control is achieved by loading in the AC generator connected to the engine this is varying the amount of fuel injected each cycle while the airflow at a given engine speed is essentially unchanged. So the governor and the fuel pump system are a necessary part.

A Sankey diagram representing the various energy flows through a modern diesel engine, is reproduced in Figure. 3 The figure represents a turbocharged engine and an indication is given of the kind of interaction between the various heat paths as they leave the cylinders after combustion. Heat released from the fuel in the cylinder is augmented by the heat value of the work done by the turbocharger in compressing the intake air [4].

Table 1.Engine Specification

\begin{tabular}{|c|c|}
\hline \multicolumn{2}{|c|}{ Engine Specification } \\
\hline Engine Type & MAK 8M453C \\
\hline Number of cylinders & 8 \\
\hline Bore & $320 \mathrm{~mm}$ \\
\hline Stroke & $420 \mathrm{~mm}$ \\
\hline Brake power(MCR) & $2650 \mathrm{kw}-3600 \mathrm{Hp}$ \\
\hline Engine Speed(MCR) & $500 \mathrm{rpm}$ \\
\hline & 1 ABB \\
\hline Turbocharger units & VTR 304-11 \\
\hline
\end{tabular}

This is apart from the turbocharger's function in introducing the extra air needed to burn an augmented quantity of fuel in a given cylinder, compared with what the naturally aspirated system could achieve. It is the objective of the marine engineer to keep the injection settings, the air flow, coolant temperatures (not to mention the general mechanical condition) at those values which give the best fuel consumption for the power developed [4]. 
The engine ratings usually indicate the highest power at which manufacturers expect their products to give satisfactory of power, economy, reliability and durability under service conditions [2].

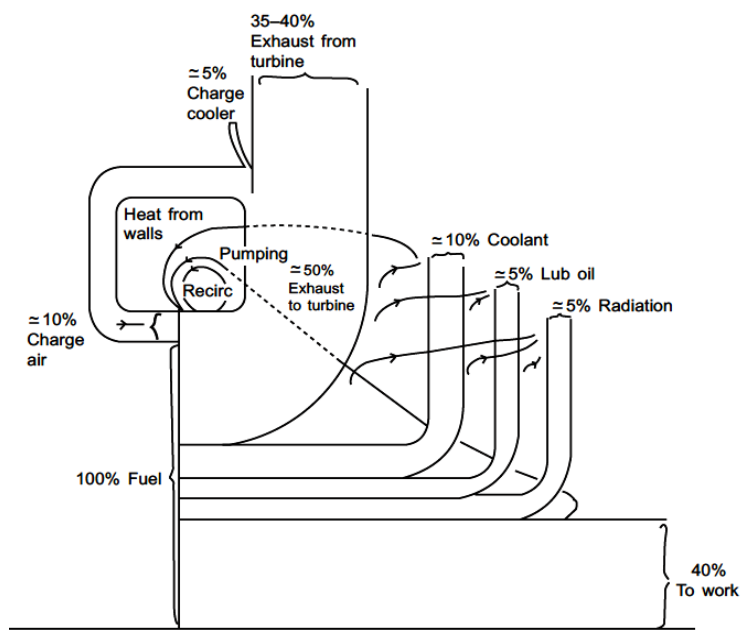

Figure 3: Typical Sankey diagram for turbocharger engines [4]

The importance of the diesel engine performance parameters are geometrical properties, the term of efficiency and other related engine performance parameters. A practical engineer wants to run an engine at all is to achieve a desired output of useful work, which is, for our present purposes, to drive a ship at a prescribed speed, and/or to provide electricity at a prescribed kilowattage.To determine this power he must, therefore, allow not only for the losses mentioned above but for the friction losses in the cylinders, bearings and gearing (if any) together with the power consumed by engine-driven pumps and other auxiliary machines.

In the diesel engine geometries design, diesel engine compression ratio is the displaced volume or swept $(\mathrm{Vd})$ and clearance volume $(\mathrm{Vc})$ divided by minimum cylinder volume $(\mathrm{Vc})$.

The diesel engine compression ratio as below:

$r_{c}=\frac{V_{C}+V_{d}}{V_{C}}$

The power delivered by the diesel engine is the product of torque and angular speed. Diesel engine power definition as,

$P=2 \pi N_{\text {eng }} Q_{E}$

Every engines efficiencies defined by Ganesan [3]. Indicated thermal efficiency $\left(\eta_{\text {ith }}\right)$ is the ratio of indicated power $(\mathrm{Pi})$ to the input fuel energy.

$$
\eta_{i t h}=\frac{P i}{\dot{m}_{f} H_{L}}
$$

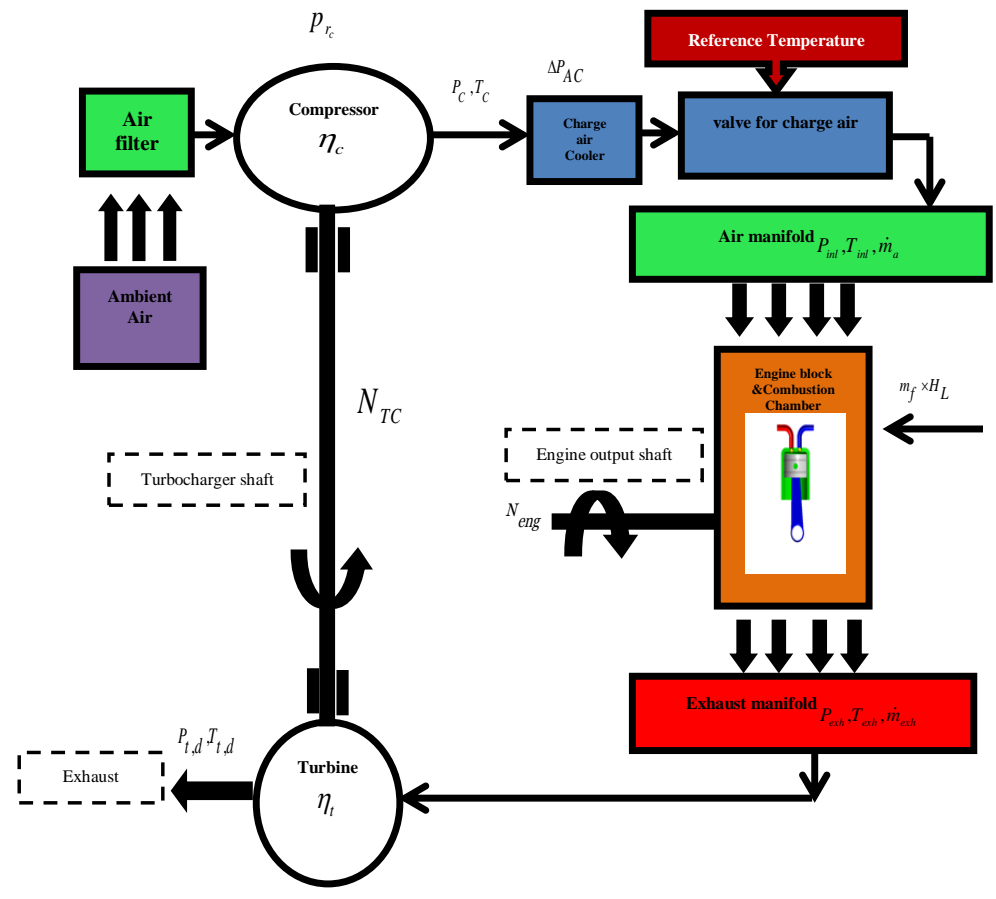

Figure. 4: Concept of the turbocharged diesel engine model with parameters.

Brake thermal efficiency $\left(\eta_{\mathrm{bth}}\right)$ is the ratio of brake power $\left(\mathrm{P}_{\mathrm{b}}\right)$

$\eta_{b t h}=\frac{P_{b}}{\dot{m}_{f} H_{L}}$

Mechanical efficiency $\left(\eta_{\mathrm{m}}\right)$ is defined as the ratio of brake power $\left(\mathrm{P}_{\mathrm{p}}\right)$ or delivered power to the indicated power $\left(\mathrm{P}_{\mathrm{i}}\right)$ or power provided to the piston and it can also be defined as the ratio of the brake thermal efficiency to the indicated thermal efficiency.

$\eta_{m}=\frac{p_{b}}{P i}=\frac{\text { output at crankshaft }}{\text { output at cylinders }}$

Relative efficiency or efficiency ratio $\left(\eta_{\text {rel }}\right)$ is the ratio of thermal efficiency of an actual cycle to that of the ideal cycle; the efficiency ratio is a very useful criterion which indicates the degree of development of the engine.

$\eta_{r e l}=\frac{\text { Actual thermal efficiency }}{\text { Air - standard efficiency }}$

The one of the very important parameters which decides the performance of four-stroke engines is volumetric efficiency, where four-stroke engines have distinct suction stroke and therefore the volumetric efficiency indicates the breathing ability of the engine. The volumetric efficiency is the volume flow rate of air into the intake system divided by the rate at which the volume is displaced by the system. The normal range of volumetric efficiency at full throttle for SI engines is $80 \%$ to $85 \%$ and for CI engines is $85 \%$ to $90 \%$ [3]. 
$\eta_{v o l}=\frac{\dot{m}_{a}}{\rho_{a} V_{d i s} N_{e n g} / 2}$

The other related engine performance was Mean effective pressure (mep), Engine Brake Torque, Brake Power and brake specific fuel consumption.

Brake Mean Effective Pressure is a good parameter for comparing engines with regard to design or output because it is independent of both engine size and speed. If brake work is used, brake mean effective pressure is obtained [7].

$B M E P=\frac{4 \pi Q_{E}}{V_{d i s}}$

Engine Brake Torque: Torque is a good indicator of an engine's ability to do work. It is defined as force acting at a moment distance $[7,12]$.

$T_{E}=\frac{V_{d i s} B M E P}{4 \pi}$

Brake Power: Power is defined as the rate of work of the engine. If $\mathrm{n}=$ number of revolutions per cycle and $\mathrm{N}_{\text {eng }}=$ engine speed, then brake power is expressed as Eq. (10) $[7,6,13]$.

$P_{b}=Q_{E} \omega_{e n g}=Q_{E}\left(2 \pi N_{e n g}\right)$

$P_{b}=L^{*} A_{P} *\left(\frac{N_{e n g}}{i}\right) * Z_{c y l} * B M E P$

Brake Specific Fuel Consumption: Brake power gives the brake specific fuel consumption $[7,6,13]$.

$B S F C=\frac{\dot{m}_{f}}{P_{b}}$

The measure of an engine's efficiency which will be called the fuel conversion efficiency is given by Heywood [2]:

$\eta_{f}=\frac{\text { heat converted into useful work }}{\text { total heat supplied }}$

$\eta_{f}=\frac{P}{m_{f} H_{L}}$

In engine testing, both the air mass flow rate, $\mathrm{m}_{\mathrm{a}}$ and the fuel mass flow rate, $\mathrm{m}_{\mathrm{f}}$ are normally measured. The ratio of these flow rates is useful in defining engine operating conditions as air/fuel ratio (A/F) and fuel/air ratio (F/A).

The air mass flow rate is calculated using the following equation, which has been derived according to the quasi-one dimensional consideration in an orifice with subsonic flow [6]:

$\dot{m}_{a}=c_{d} A_{e q} \frac{p_{\text {inl }}}{\sqrt{R_{a} T_{i n l}}} f\left(p_{e x h} / p_{i n l}, \gamma_{\alpha}\right)$

Where:

$f\left(\frac{p_{e x h}}{p_{i n l}}, \gamma_{\alpha}\right)=\sqrt{\frac{2 \gamma_{\alpha}}{\gamma_{\alpha}-1}\left[\left(\frac{p_{e x h}}{p_{\text {inl }}}\right)^{\frac{2}{\gamma_{\alpha}}}-\left(\frac{p_{e x h}}{p_{\text {inl }}}\right)^{\frac{\gamma_{\alpha}+1}{\gamma_{\alpha}}}\right]}$

In the case of four-stroke engines, the following amount, which accounts for the mass flow rate due to the air pumping of the engine, must be added to the respective one derived by applying equation [6]:

$m_{\text {pump }}=\eta_{v o l} \rho_{a, \text { inl }} V_{d} N_{\text {eng }} / 120$

The engine brake mean effective pressure is calculated by subtracting the friction mean effective pressure from the indicated mean effective pressure. The indicated mean effective pressure is calculated using the rack position, the maximum indicated mean effective pressure of the engine and the combustion efficiency, which in turn is regarded as function of air to fuel ratio [6],combustion efficiency are approximated using manufacturer sea trial with help of equ.16:

$I M E P=X_{r} I M E P_{, \max } \eta_{\text {comb }}$

The friction mean effective pressure is considered function of the indicated mean effective pressure and the engine crankshaft speed [6]:

$F M E P=k_{f o}+k_{f_{1}} N_{\text {eng }}+k_{f_{2}} I M E P$

Where $k_{f o}, k_{f 1}, k_{f 2}$ are constants.

For the calculation of the fuel mass flow rate, the variation of the mass of injected fuel per cylinder and per cycle vs. fuel rack position must be provided as input. Thus, for each value of rack position, the fuel mass flow rate is calculated by:

$\dot{m}_{f}=Z_{c y l} m_{f, c y} N_{e n g} / 2$

\subsection{Engine Cylinder Model}

The energy balance applied on engine cylinders gives:

$\left(\dot{m}_{\alpha_{p, a}} \boldsymbol{T}_{\text {inl }}+\eta_{\text {comb }} \dot{m}_{f} H_{L} \zeta\right) \eta_{e x h}=\left(\dot{m}_{a}+\dot{m}_{f}\right) \mathcal{c}_{p, e x h} T_{e x h}$

In order to calculate the engine shaft and the turbocharger shaft speeds as in equations (20),(26), which are derived by applying the angular momentum conservation in the engine shafting system and the turbocharger shaft respectively. The equations (7), (34), (18), (17) required for the calculation procedure of 
engine speed and turbocharger speed equations $[6,14$, 13].

The air and gas properties, the fuel lower heating value, the discharge coefficient and the correction factor for the exhaust gas temperature are considered to be constant. The pressure and temperature of the air contained in the inlet manifold are calculated by modelling the compressor and the air cooler.

$\frac{d N_{e n g}}{d t}=\frac{\eta_{s h} \eta_{G B} i_{G B} Q_{e n g}-Q_{p}}{I_{E}+I_{G B}+I_{s h}+I_{P}}$

In the case where engine modelling is only of interest, i.e. the propeller and ship models will not be used, the propeller torque, required in eq. (20), is calculated according to the propeller law through the engine maximum continuous rating (MCR) operating point, as follows [13,12] .

$Q_{P}=k_{p} N_{e n g}^{2}$

$k_{p}=Q_{\text {eng }, M C R} / N_{e n g}^{2}, M C R$

\subsection{Modelling of Engine Governor}

The speed control of engines is intimately associated with the origins of control theory. These are many examples in the ancient times of devices that could be said to incorporate feedback or regulation, and most basic control textbooks will have some discussion of the ancient origins of feedback mechanisms. The main purpose of the governor is to regulate the position of the engine fuel servo in order to maintain an engine speed equal to a reference setting. The governor system is composed of two separate parts: the speed regulating function and the fuel actuating function [2].A PID (proportional-integral-differential) engine governor model was chosen and implemented in MATLAB Simulink environment. According to that, the following equation is used for the calculation of the engine rack position:

$x_{r}=x_{r, o}+k_{p} \Delta N+k_{i} \int_{0}^{t} \Delta N d t+k_{d} \frac{d(\Delta N)}{d t}$

Where $\Delta N=N_{\text {ord }}-N_{\text {eng }}$ is the difference between the ordered engine speed and the actual engine speed. The engine governor model is depicted in figure 5 . As it is shown in that figure, an engine torque limiter has also been incorporated in the engine governor model. Its function is to limit the engine governor rack position to a predetermined maximum value depending on the engine speed, in order to protect the engine integrity during fast transients or over speed.

Electronic governors used nowadays are mainly PID control based. From simulation or operational experiences a set of optimal PID gains are selected and switching between different sets of PID gains is carried out according to the actual operation conditions, thus achieving better performance than mechanical hydraulic governors which basically have fixed gains.

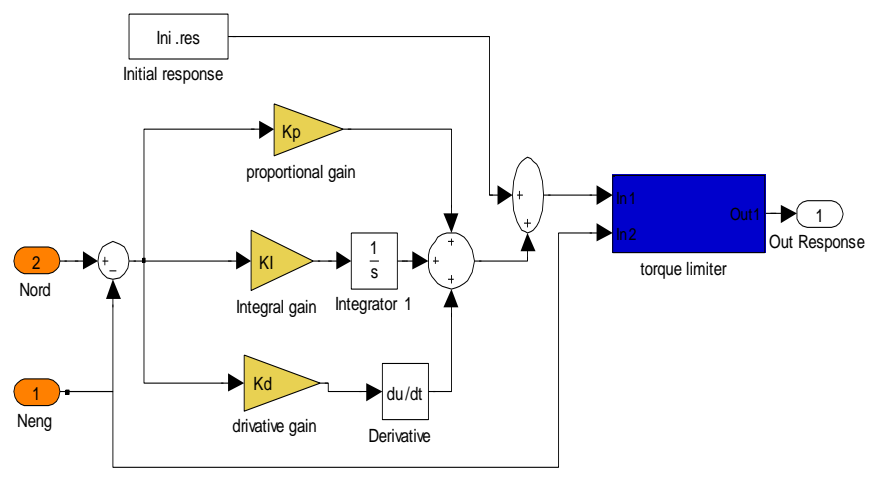

Figure 5 Engine governor modeled as PID Controller

On the other hand electronic governors based on fuzzy control and optimal control; however control algorithms are expected to get complicated.

\subsection{Turbocharger Model}

In order to identify the engine model. The model should also be accurate enough to predict engine behaviour under operational conditions. Many researchers have been done to simulate the engine dynamic behaviour in order to simulate the dynamic performance of engine. To model the engine performance required information such as turbocharger maps, torque generation efficiency, geometric and dynamic characteristics of engine are collected from the manufactures' catalogue for ABB turbocharger and MAK engines [16].

Turbocharger model comprises compressor, turbine and interconnecting shaft. There are different methods for modelling the dynamic performance of turbochargers. In this simulation a simple yet accurate model is used. In order to compress the inlet air, mechanical energy is fed to compressor; the required mechanical torque is calculated using the following formula:

$Q_{\text {Comp }}=\dot{m}_{d} C_{p a}\left(T_{c}-T_{a}\right) /\left(2 \pi N_{T_{c}}\right)$

The turbine wheel delivered torque is given by:

$Q_{\text {tur }}=\dot{m}_{e x h} C_{p e x h}\left(T_{e x h}-T_{t u r, d}\right) /\left(2 \pi N_{T C}\right)$

Exhaust gas mass flow rate through the turbine is a function of turbine pressure ratio and turbine shaft speed. Also the turbine efficiency is a function of air flow Mach number and turbine shaft speed [6].

The rotational acceleration of the turbo shaft is derived through Newton's second law describing the power transfer within the turbocharger as follows. [11-14] 


$$
\frac{d N_{T C}}{d t}=\frac{Q_{\text {tur }}-Q_{\text {Comp }}}{I_{T C}}
$$

Where $I_{t c}$ is the rotational inertia of inter connecting shaft.By applying the mass balance in the engine, as well as by using the quasi-one dimensional consideration for calculating the exhaust gas mass flow rate through the turbine [6].Equation (27) is used for subsonic flow and equation (28) for sonic flow:

$\dot{m}_{e x h}=\dot{m}_{a}+\dot{m}_{f}=A_{\text {turesf }} \frac{p_{e x h}}{\sqrt{R T_{e x h}}} f\left(p_{\text {tur } d} / p_{e x h}, \gamma_{e}\right)$

$\dot{m}_{a h}=\dot{m}_{a}+\dot{m}_{f}=A_{\text {ure eff }} \frac{p_{a b h}}{\sqrt{R T_{e n h}}} \sqrt{\frac{2 \gamma_{e}}{\left(\gamma_{e}-1\right)}\left(\frac{2}{\gamma_{e}+1}\right)^{\frac{\gamma_{+}+1}{\gamma_{e}-1}}}$

The mass of fuel injected can be defined as a function of relative fuel rack position:

$\dot{m}_{f}=\dot{m}_{f, M C R} X_{r}$

\subsection{Gas Turbine Model}

The gas turbine constitutes one of the two main parts of the turbocharger. It is driven by exhaust gas from the exhaust manifold and is itself the power source of the compressor through the turbo shaft connection.

The turbine effective flow area is derived from the turbine geometric area and the turbine flow coefficient, which, in turn, is considered function of the turbine pressure ratio [6].

$A_{\text {tur }, \text { eff }}=\alpha_{t} A_{t, \text { geo }}$

With

$$
\alpha_{t}=k_{t 0}+k_{t 1} p_{r_{t}}+k_{t 2} p_{r_{t}}{ }^{2}
$$

Using the turbine efficiency definition equation and after some manipulation, the following equation is derived for the calculation of the temperature of the exhaust gas exiting turbine [6]:

$\boldsymbol{T}_{t, d}=\boldsymbol{T}_{e x h}\left(1-\eta_{t}\left[1-\left(p_{t u r, d} / p_{e x h}\right)^{\left(\gamma_{e}^{-1}\right) / \gamma_{e}}\right]\right)$

The turbine efficiency is taken as a function of the turbine pressure ratio, or alternatively of the turbine velocity ratio. The pressure after the turbine is calculated using the pressure increase of the exhaust piping system:

$p_{t u r, d}=p_{a}+\Delta p_{e p}=p_{a}+\frac{f_{e p} \dot{m}_{e x h}^{2}}{2 \rho_{e p} A_{e p}^{2}}$

\subsection{Air Filter Model}

The main task of the air filter is to separate the incoming air from rough particles. It also has noise, pressure and temperature reducing functions. The temperature change through the air filter is proportional to the air flow $\mathrm{m}_{\mathrm{a}}$ as follows, where $\mathrm{T}_{\mathrm{af}}$ is the air temperature within the air filter, $\mathrm{T}_{\mathrm{amb}}$ the air temperature outside the engine and $\mathrm{k}_{\mathrm{af}}$ a constant [11].

$\mathrm{T}_{A F}=\mathrm{T}_{\text {amb }}+K_{A F} \dot{m}_{a}$

\subsection{Air Compressor Model}

The compressor is usually modeled using its performance map. However, in marine applications, where it can be assumed that the engine is loaded according to the propeller law, the compressor operating points lay on a single curve, which can be represented by the following equation:

$P_{r c}=k_{c} N_{T C}^{2}+1$

The compressor efficiency can also be assumed constant, or for greater accuracy, its variation with turbocharger shaft speed can be taken into account. Thus, the compressor exiting air temperature is calculated using equation [36], which has been derived using the compressor efficiency definition [6].

$T_{C}=T_{a}\left(1+\left(p_{r c}^{\left.\left(\gamma_{a}-1\right) / \gamma_{a}-1\right)} / \eta_{C}\right)\right.$

\subsection{AIR COOLER MODEL}

The air cooler is modeled in a rather simple way compared to the turbocharger, based on experimental data from the engine shop trials. The pressure drop and the effectiveness are given as functions of the mass flow rate through it [8] as follows,

$\varepsilon=1-k_{A C} \dot{m}_{a}^{2}$

The pressure drop in the air cooler is calculated by [6] as,

$\Delta p_{A C}=f_{A C} \frac{\rho}{2} V^{2}=\frac{f_{A C} R T_{C} \dot{m}_{a}^{2}}{2 p_{C} A_{A C}^{2}}$

It can be approximated according to $[7,12]$ as,

$$
\Delta P_{A C}=k_{P a c} \dot{m}_{a}^{2}
$$

Where $\mathrm{k}_{\mathrm{pac}}$ is a constant

The temperature of air exiting air cooler, which is equal to the inlet manifold temperature, is calculated using the air cooler effectiveness and the temperature of the air cooler coolant medium $[6,13,15]$.

$T_{i l l}=T_{c}-\varepsilon\left(T_{c}-T_{W}\right)$

Where is the $\varepsilon$ effectiveness defined as [7]

$\mathcal{E}=\frac{T_{i n, a}-T_{a, o u t}}{T_{a, i n}-T_{w, i n}}$ 
The air cooler effectiveness can be also modeled as a function of the air mass flow rate [6]:

$$
\boldsymbol{\varepsilon}=k_{A C 0}+k_{A C 1} \dot{m}_{a}+k_{A C 2} \dot{m}_{a}^{2}
$$

The pressure of the air contained in the inlet receiver is calculated by:

$p_{i n l}=p_{C}-\Delta p_{A C}=p r_{C} p_{a}=\Delta p_{A C}$

The proportion of the chemical energy of the fuel contained in the exhaust gas is considered linear function of the engine mean effective pressure [6] as,

$\zeta=k_{z_{0}}+k_{z_{1}} B M E P$

The exhaust gas pressure in the exhaust manifold, the turbine inlet total pressure is assumed to be equal to the exhaust receiver pressure [8].

$\mathrm{P}_{\mathrm{exh}}=\mathrm{P}_{\mathrm{amb}}+\mathrm{P}_{\text {back }}$

Where $\mathrm{P}_{\text {back }}$ is $\mathrm{t}$ he back pressure.

$P_{b a c k}=a_{e x h} m_{e x h}^{2}$

Constant $a_{\text {exh }}$ is estimated from the constants determination procedure using the exhaust Back pressure values reported in the engine shop trials [9].

\section{VALIDATION OF MODEL PARAMETERS USING EXPERIMENTAL MEASUREMENTS}

The activities have been performed one or several times during the process, which is described schematically in figure1. The process started with study of theory and earlier works. After the first reading phase, the design of the measurement setup was done and the measurements started. Then, the measured signals were analyzed and if necessary, the designs of the measurement setup were changed. In parallel to the design of the measurement setup and the measurement, the modeling activity started and was followed by the implementation. The implemented model was then validated and, furthermore, the results were analyzed. If the result was good enough, the process was ended and if the result was not to satisfaction, the procedure was repeated from the study or modeling phase until satisfaction. Measurements were performed in a diesel engine. Signals from sensors specially installed. Data from sensors were collected by the measurement system. The quantities measured were pressure, temperature, engine speed, brake power and turbocharger speed. The measurement is carried out using different devices. The same signal is measured using two different devices to ensure the measurement is right and to match the two reading. Comparison of the reading is carried out in pressure and temperature measurements to ensure the measured signals are correct.

\section{CONCLUSION}

In this paper model has been designed for assessing the quality and reliability of the diesel engine system under aggravated conditions. The model consists of components whose mathematical descriptions have been derived from basic laws of mechanics, thermodynamics, dynamics and fluid dynamics, mutually correlated by flows for the transfer of mass and energy. The numerical model has been implemented on the computer using the application MATLAB 2008- SIMULINK. By applying some modifications and entering appropriate parameters, the proposed simulation model can be applied to any diesel engine system with a turbocharged four-stroke diesel engine with. Comparison of calculated results obtained from the model with shop trial data, its ability to predict engine behavior accurately is confirmed. The model manages to predict the behavior of the various engine subsystems as well, while the most encouraging is its ability to predict adequately the exhaust gas temperature, which is generally recognized to be one of the most difficult engine parameters to predict.

From the simulation model it is show that the main reason for exhaust gas temperature increase is the reduction of air mass flow rate through the engine

Also it is interesting to see that air cooler, exhaust port, and exhaust duct and turbine inlet flow area reduction affect the exhaust gas temperature level. Furthermore, it is observed that various faults may cause the same overall effect on the engine. The simulation model provides valuable information in this direction making it possible to distinguish various faults and to develop a database concerning their effect on engine performance. This process is extremely faster and has a lower cost compared to the experimental methods used by various manufacturers. We believe that it is important for marine diesel engines. Furthermore, since the simulation model used in the present work is a general one, the proposed method can also be extended to other types of diesel engines.

In this paper the simulation model has been applied for analyzing a diesel engine of generator system consisting of a four-stroke turbocharged diesel engine. The model's examination shows a close correspondence between the designed and the measured engine's performance for stationary operating points in a wide load range from 5 $\%$ to $110 \%$. In addition to referential environment conditions. It adequately predicts the engine speed response and in that respect, it can be reliably used in the engine speed control design process. In order to represent with acceptable accuracy the turbocharger shaft speed response during fast transients. Thus, for advanced engine speed control, turbocharger such a model should be carefully treated. The engine physical processes are more accurately represented since this approach includes the more detailed modeling of the engine. In that respect, 
the model gives better predictions for the engine operating parameters response during fast transients.
Finally, it can also be used for educational purposes, in order for the students.

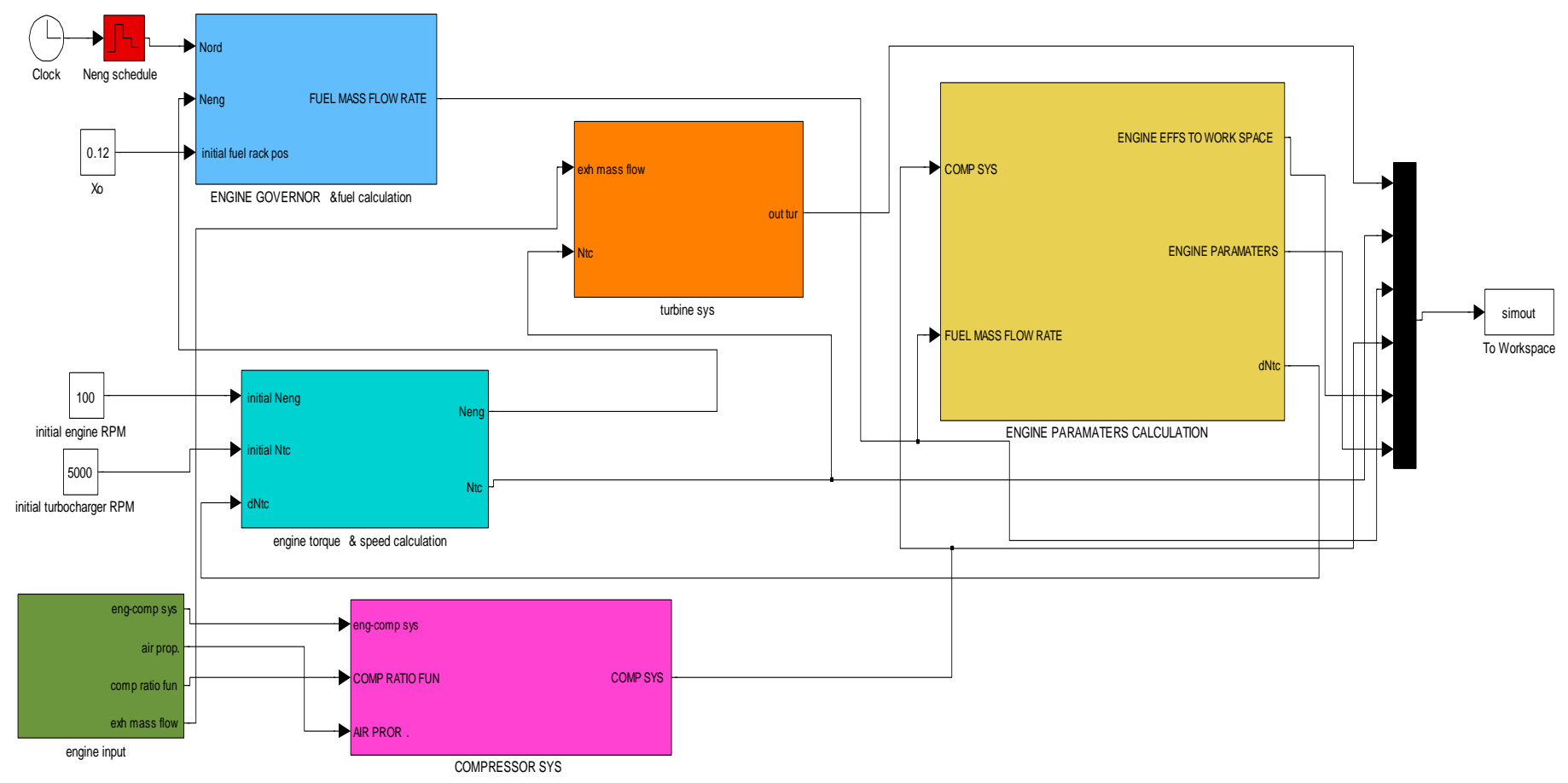

Figure 6.Overall 4- stroke diesel engine Mak 8M453C simulink model of Mashour cutter suction generator engine.

\section{REFERENCES}

[1] Semin, Rosli Abu Bakar, Abdul Rahim Ismail, Investigation of Diesel Engine Performance Based on Simulation, American Journal of Applied Sciences 5 (6), 2008.

[2] J.B Heywood, Internal Combustion Engines Fundamentals, Mc-Graw Hill, 1988.

[3] V.Ganesan, Internal Combustion Engine, 2nd Ed., Tata McGraw-Hill, 2003.

[4] Doug Woodyard, Pounder's Marine Diesel Engines and Gas Turbines, Eighth edition, Edited 2004.

[5] Engineer handbook MAK, Service document of Caterpillar Motoren, Edited 1995.

[6] G. P. Theotokatos, A Modelling Approach for the Overall Ship Propulsion Plant Simulation, $6^{\text {th }}$ WSEAS International Conference on SYSTEM SCIENCE and SIMULATION in ENGINEERING, Venice, Italy, 2007.

[7] Rafidah Rahim, Rizalman Mamat, Mohd Yusof Taib and Abdul Adam Abdullah, Influence of Fuel Temperature on a Diesel Engine Performance Operating with Biodiesel Blended, International Journal of Advanced Science and Technology, June, 2012.
[8] Dimitrios T. Hountalas, Prediction of marine diesel engine performance under fault conditions, Applied Thermal Engineering, Greece, 2000

[9] MAK, Engine operating instructions type M453C, 2000.

[10] Bernard Challen and Rodica Baranescu, Diesel Engine Reference Book, Second Edition, 1999

[11] Magnus Ramstedt, Cylinder-by-Cylinder Diesel Engine Modelling - A Torque-based Approach Master's thesis performed in Vehicular Systems ,2004

[12] Giovanni benvenuto,ugo campora, proformance preidiction of a faulty marine diesel engine under different governor settings, Genova university , Italy ,2005

[13] Gerasimos P. Theotokatos, Ship Propulsion Plant Transient Response Investigation using a Mean Value Engine Model, International journal of energy, 2008.

[14] Anna stefanopoulou and Roy smith, Maneuverability and smoke emission constraints in marine diesel propulsion, Control Engineering Practice8 -2000.

[15] Jianyuan Zhu,Modeling and Simulating of Container Ship's Main Diesel Engine, Proceedings of the International Multi Conference of Engineers and Computer Scientists , Hong Kong ,2008.

[16] ABB turbo systems, operation manual of $\mathrm{ABB}$ $\begin{array}{llll}\text { turbocharger } & \text { VTR } & 304-11, & \end{array}$ 

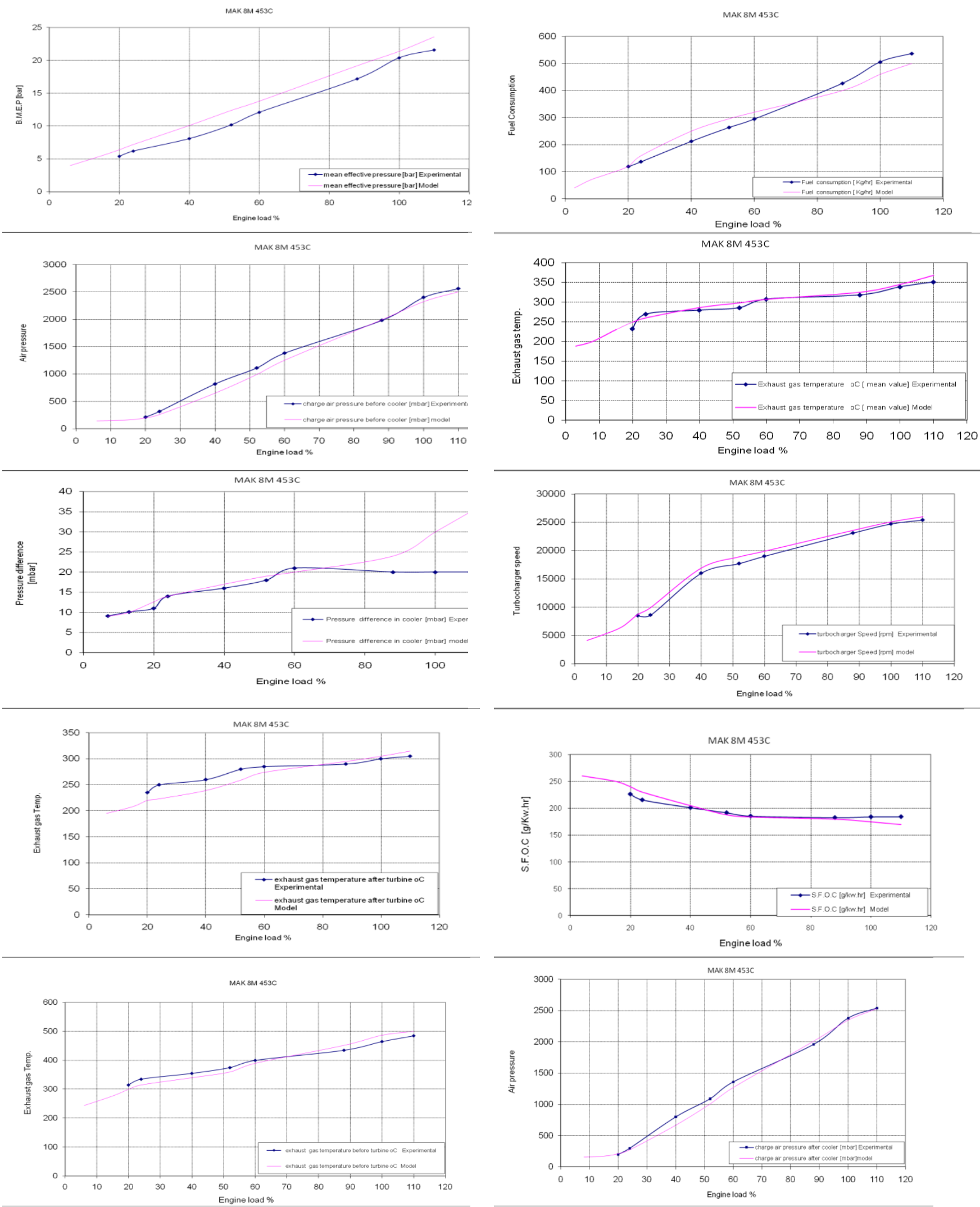

Figure 7. Comparison of simulation results to experimental data: steady state performance for 8M MAK 453C 


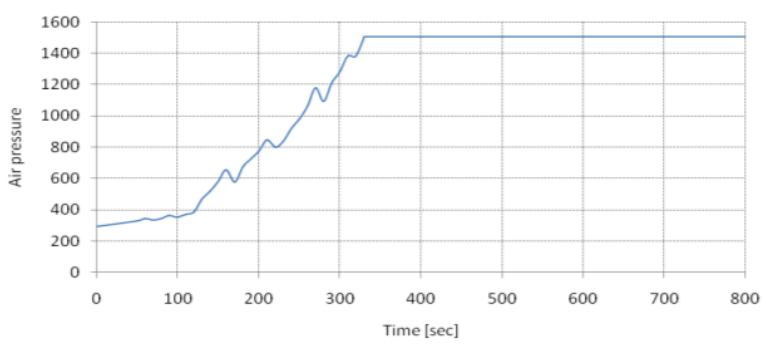

_charge air pressure after cooler [mbar]
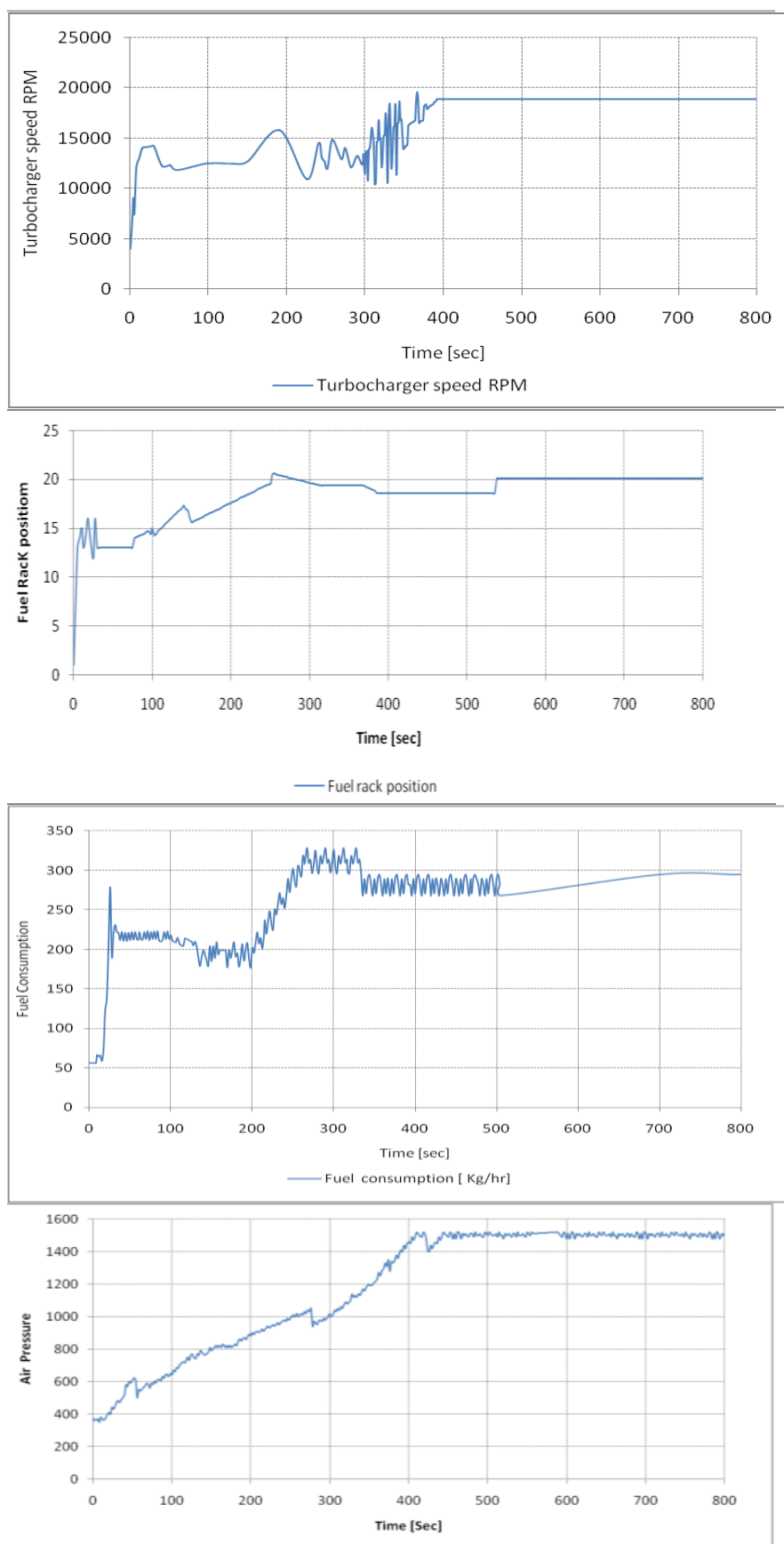

Figure 8. Transient results of engine simulation for MAK 8M 453C at $60 \%$ load

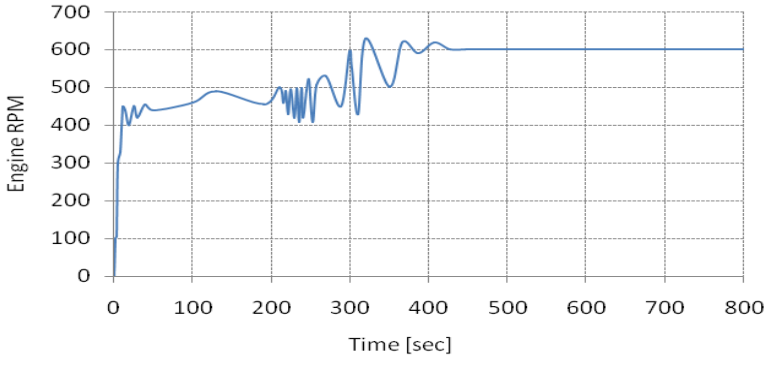

- engine RPM

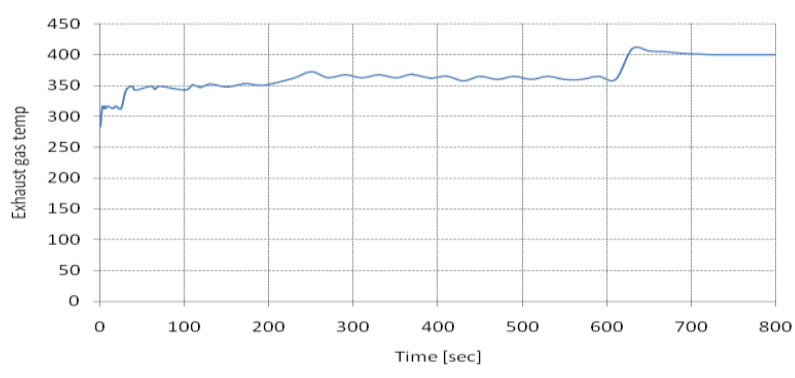

- exhaust gas temperature before turbine oc
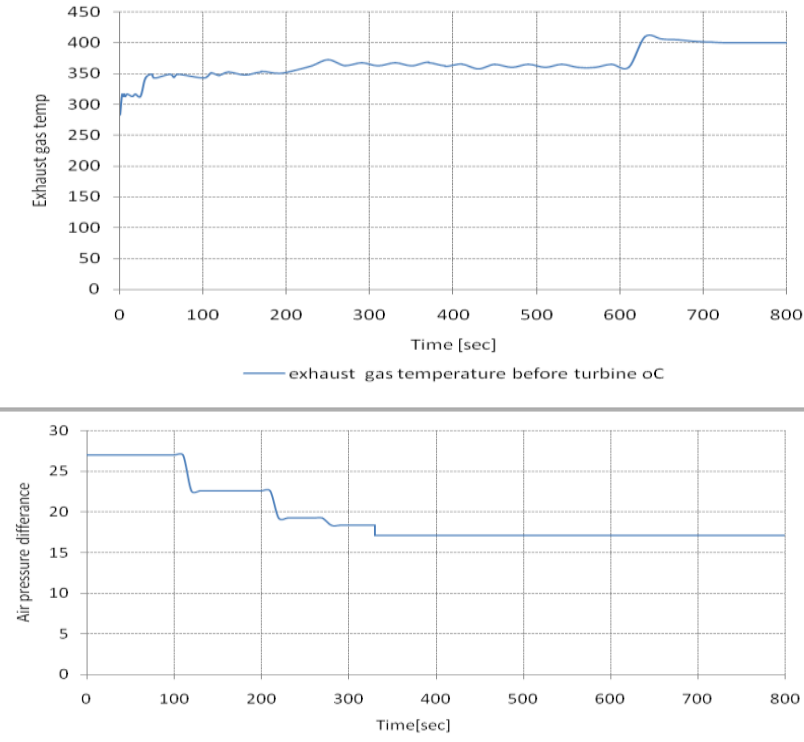

Pressure difference in air cooler [mbar]

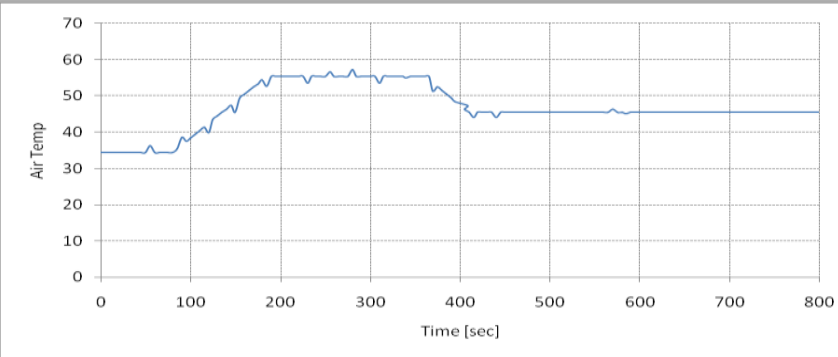

_charge air temp outlet to air coole 

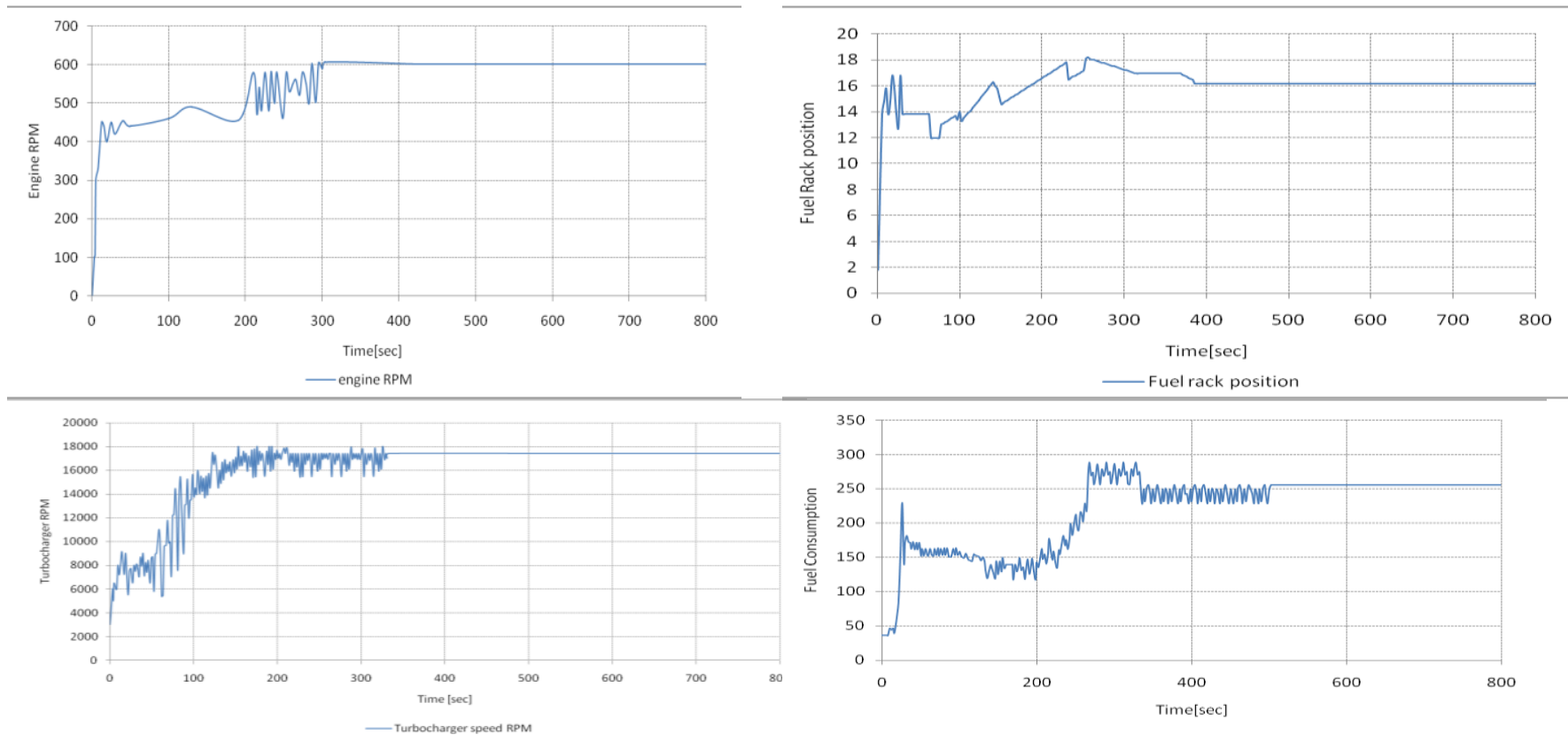

_ Fuel consumption [ $\mathrm{Kg} / \mathrm{hr}]$
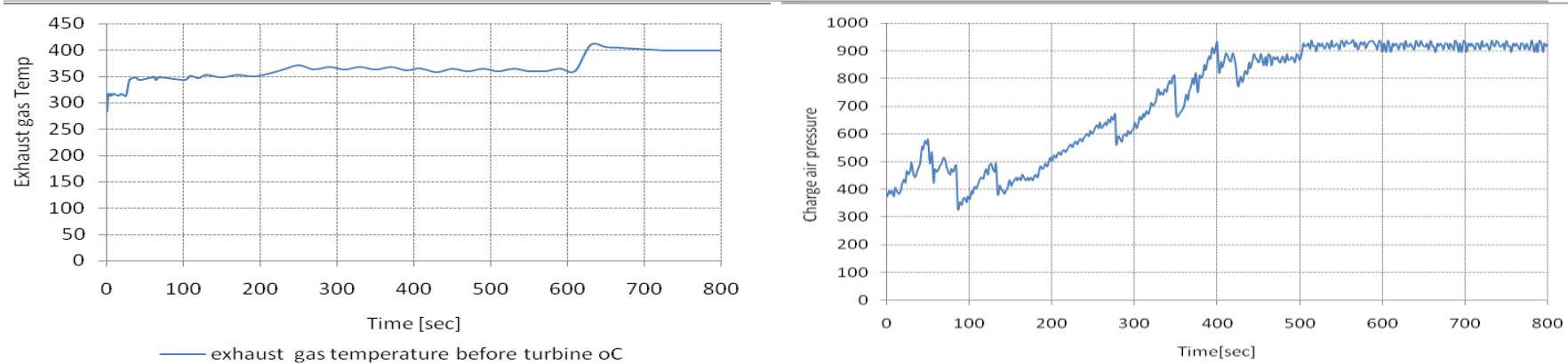

_ exhaust gas temperature before turbine oc
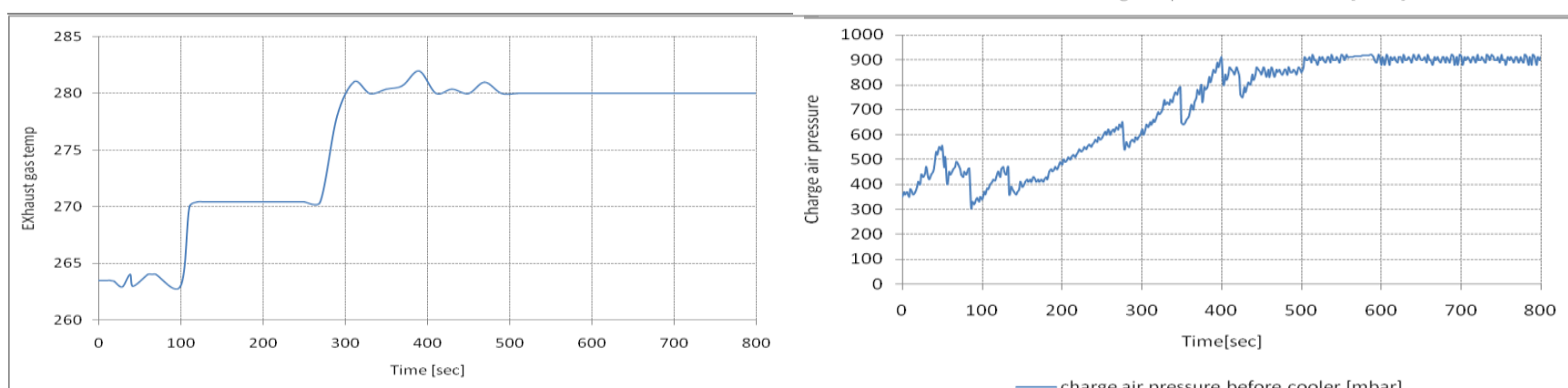

_ exhaust gas temperature after turbine...
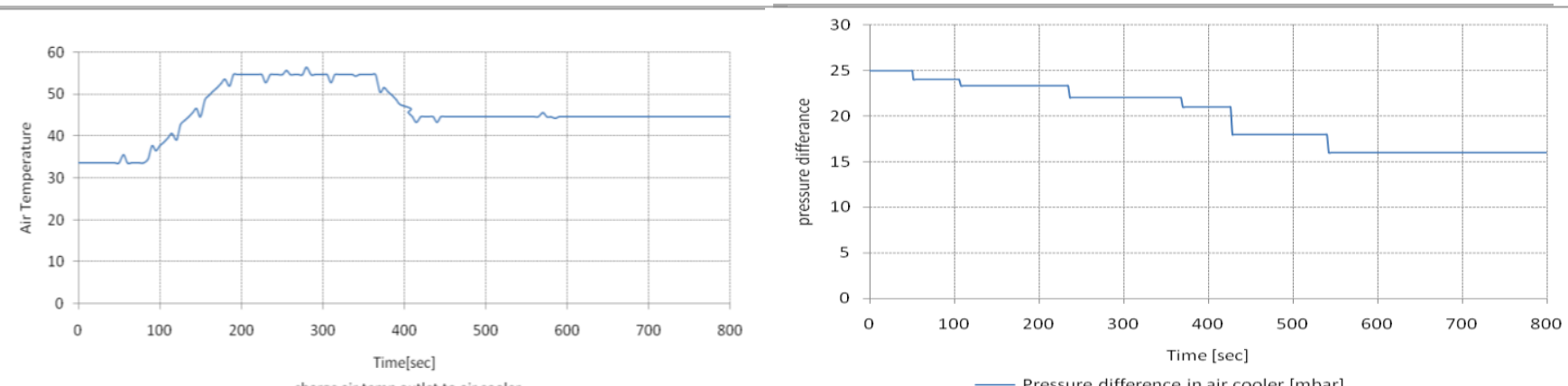

Figure 9. Transient results of engine simulation for MAK 8M 453C at 50\% load 


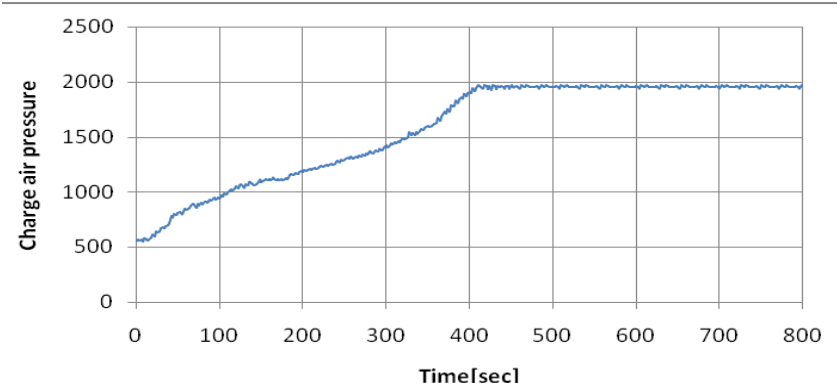

_charge air pressure before cooler [mbar]

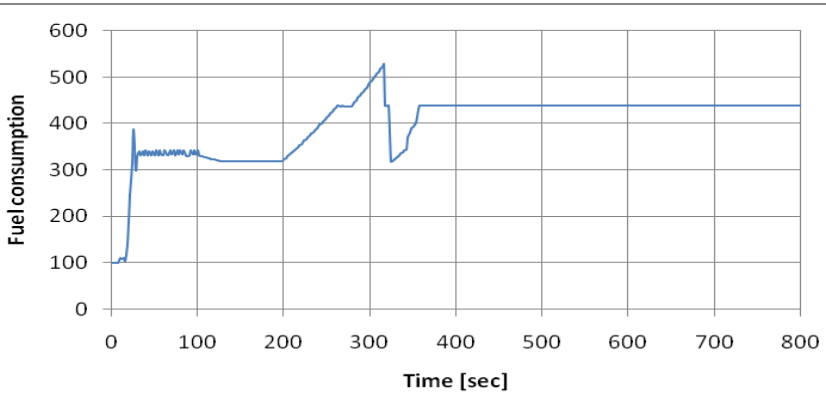

- Fuel consumption [ $\mathrm{Kg} / \mathrm{hr}]$

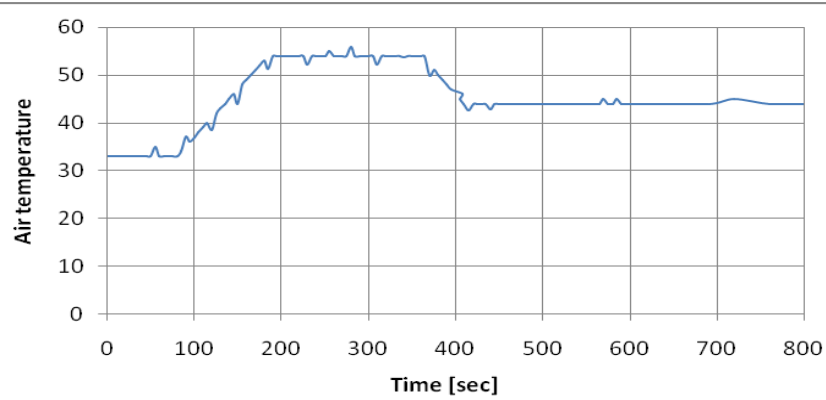

_ charge air temp outlet to air cooler

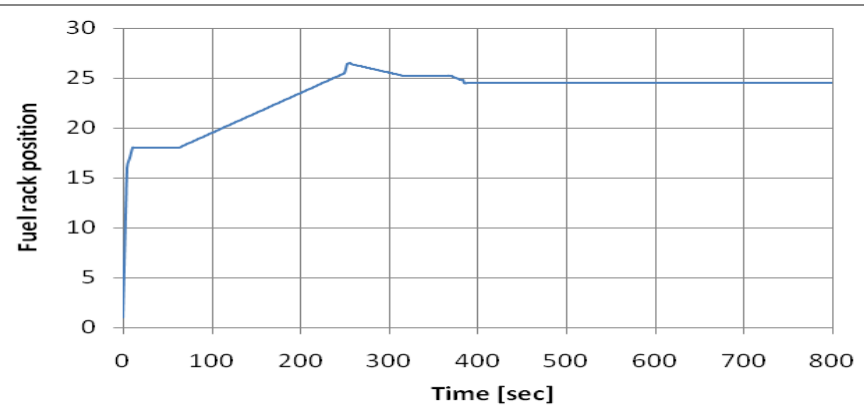

fuel rack position

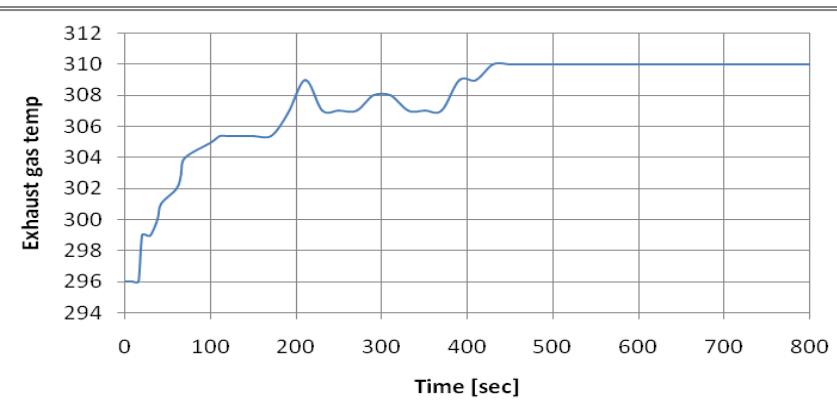

_ exhaust gas temperature after turbine oc

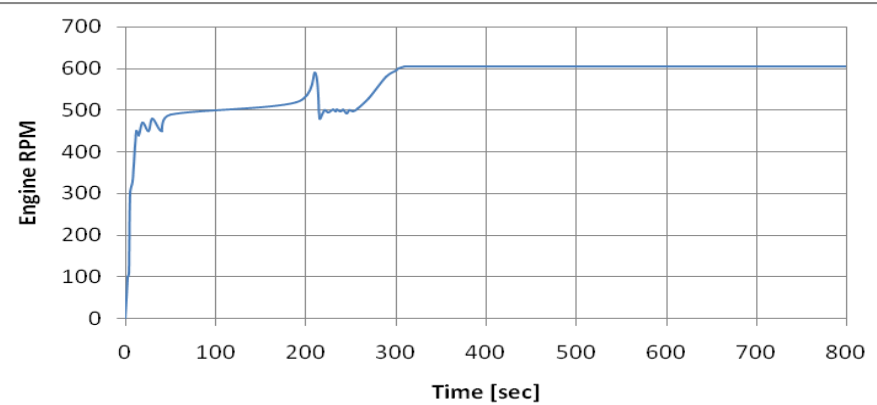

- engine RPM
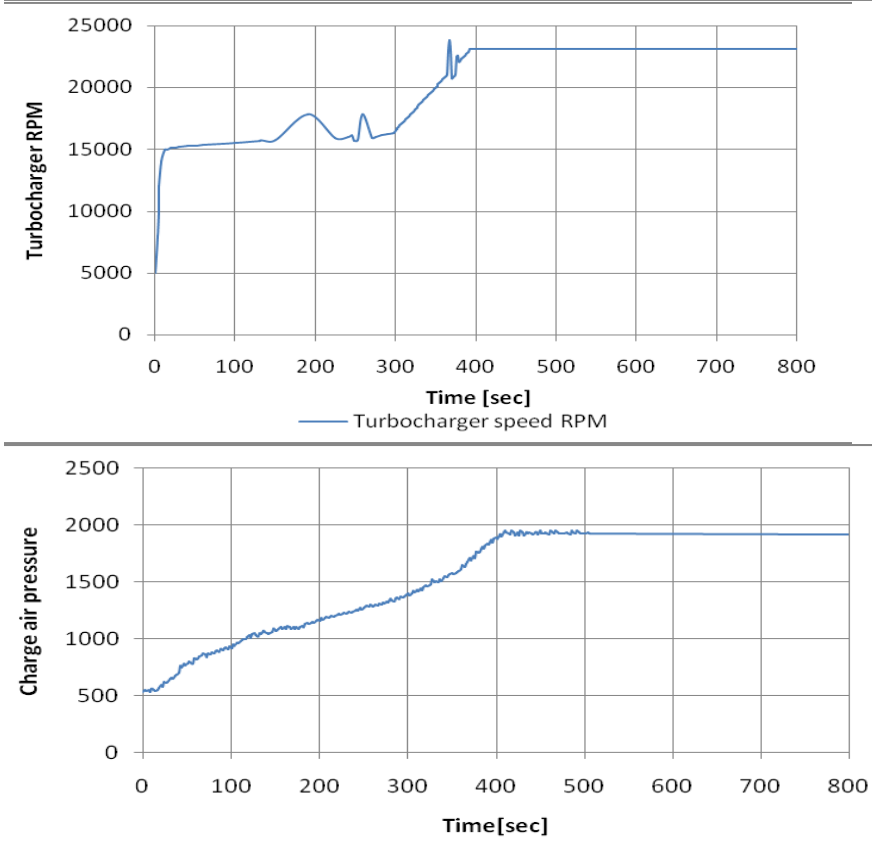

_ charge air pressure after cooler [mbar]
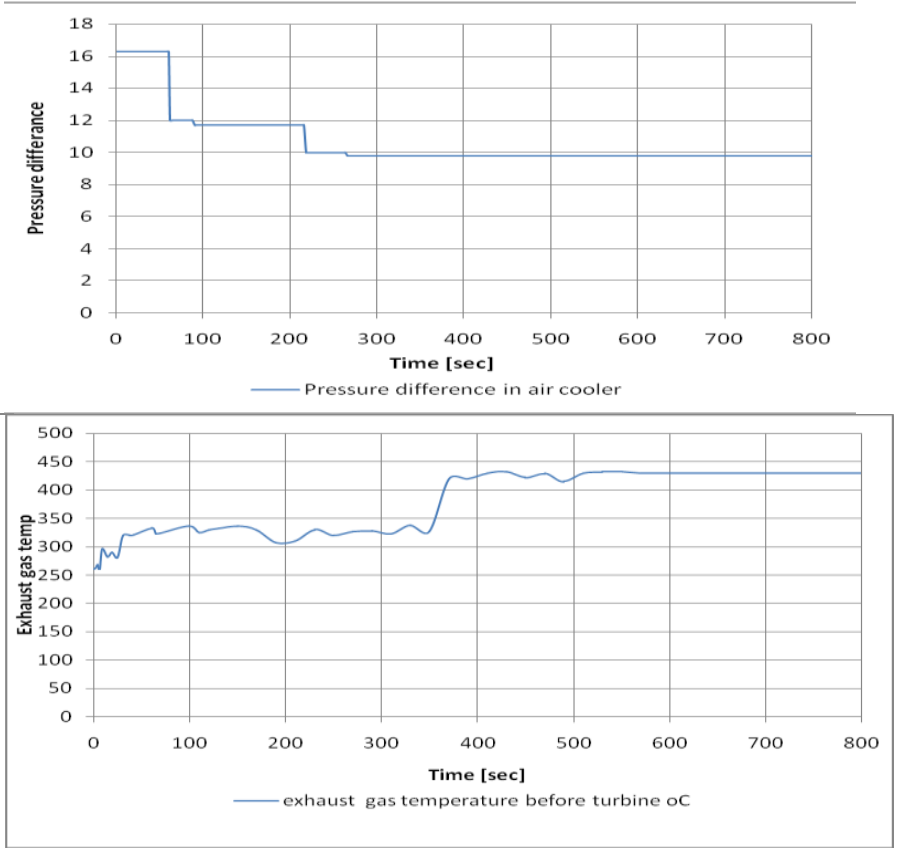

Figure 10. Transient results of engine simulation for MAK $8 M 453 \mathrm{C}$ at $85 \%$ load. 